\title{
Treatment of Hypercholesterolemia With PCSK9 Inhibitors in Heart Transplant Recipients. First Experience in Spain
}

\author{
Tratamiento de la hipercolesterolemia con inhibidores de la PCSK9 en receptores de \\ trasplante cardiaco. Primera experiencia en España
}

\author{
María del Val Groba-Marco ${ }^{a}$, Samuel del Castillo-Garcíab ${ }^{\mathrm{b}}$, Gonzalo Barge- \\ Caballero $^{\mathrm{c}, \mathrm{d}, \mathrm{e},}$, Eduardo Barge-Caballero ${ }^{\mathrm{c}, \mathrm{d}, \mathrm{e}}$, David Couto-Mallón ${ }^{\mathrm{c}, \mathrm{d}, \mathrm{e}}$, María G. Crespo- \\ Leiro $^{\mathrm{c}, \mathrm{d}, \mathrm{e}}$
}

\author{
${ }^{a}$ Unidad de Insuficiencia Cardiaca, Servicio de Cardiología, Hospital Universitario de Gran Canaria Doctor \\ Negrín, Las Palmas de Gran Canaria, Spain \\ ${ }^{b}$ Servicio de Cardiología, Complejo Asistencial Universitario de León, León, Spain \\ ' Unidad de Insuficiencia Cardiaca Avanzada y Trasplante Cardiaco, Servicio de Cardiología, Complexo \\ Hospitalario Universitario A Coruña, A Coruña, Spain

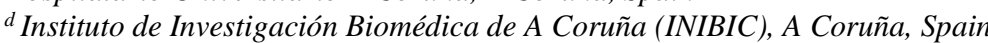 \\ ${ }^{e}$ Centro de Investigación Biomédica en Red Enfermedades Cardiovasculares (CIBERCV), Instituto de Salud Carlos \\ III, Madrid, Spain
}

\section{To the Editor,}

Hypercholesterolemia continues to be an important comorbidity often seen in heart transplant (HT) recipients and is associated with a higher cardiovascular risk and with the appearance of graft vascular disease (GVD). ${ }^{1}$ Statin therapy in this patient group has been shown to significantly reduce the incidence of acute graft rejection and GVD and to increase survival, benefits attributable not only to lower plasma cholesterol concentrations but also to the immunomodulatory effects of statins. ${ }^{2}$ Consequently, clinical practice guidelines recommend long-term use in all HT recipients, regardless of low-density lipoprotein cholesterol (LDL-C) levels. ${ }^{3}$

Proprotein convertase subtilisin/kexin type 9 (PCSK9) selectively binds to LDL-C receptors in the hepatocyte membrane, enhancing receptor breakdown and indirectly raising plasma LDL-C concentrations. The PCSK9 inhibitors (PCSK9i) known as alirocumab and evolocumab are monoclonal antibodies that block the activity of this protein, and they have been shown to significantly reduce LDL-C and the risk of cardiovascular events. ${ }^{4}$ Furthermore, PCSK9 metabolism does not involve cytochrome P450 or certain hepatic carriers, such as organic anion transporting polypeptide C (OATP-C), which play a key role in the process that breaks down statins and common immunosuppressant drugs, thereby dramatically reducing the likelihood of drug interactions and adverse reactions. Hence, this pharmacological group is an interesting therapeutic alternative for the treatment of hypercholesterolemia in HT recipients, although there is currently little evidence on its safety and efficacy in this population. We describe a series of $5 \mathrm{HT}$ recipients who began taking PCSK9i due to LDL-C > 100mg/dL despite ezetimibe therapy and, when tolerated, the highest dose of a statin, as recommended in the therapeutic positioning report published by the Ministry of Health, Consumer Affairs and Social Welfare of the Government of Spain. All patients were men, the mean age was $58.8 \pm 8$ years, and the mean post-HT time was $13 \pm 5.2$ years. In all patients, the immunosuppressant regimen included 3 drugs, and in 3 patients (patients 3, 4, and 5), the presence of GVD had been previously confirmed. Patients 1, 2, and 5 were receiving a combination of rosuvastatin $40 \mathrm{mg} / \mathrm{d}$ and ezetimibe $10 \mathrm{mg} / \mathrm{d}$; patient 3 was receiving only 
ezetimibe $10 \mathrm{mg} / \mathrm{d}$ due to a history of liver and muscle toxicity with several statins, and patient 4 was receiving a combination of pitavastatin $4 \mathrm{mg} / \mathrm{d}$ and ezetimibe $10 \mathrm{mg} / \mathrm{d}$ following muscular toxicity with other, more potent statins (Table 1).

The PCSK9i administered to all patients was subcutaneous alirocumab 75mg/14d, for a mean of $15.6 \pm 6.5$ months. Mean baseline levels for total cholesterol, LDL-C, high-density lipoprotein cholesterol (HDL-C), and triglycerides were $262 \pm 21,155 \pm 19,60 \pm 14$, and $227 \pm 41 \mathrm{mg} / \mathrm{dL}$, respectively, and dropped to $150 \pm 33$, $61 \pm 23,58 \pm 19$, and $153 \pm 63 \mathrm{mg} / \mathrm{dL}$ by the end of follow-up. All patients reached the target of LDL-C $<100 \mathrm{mg} / \mathrm{dL}$, with percent reductions of $45 \%$ to $76 \%$ (Figure 1).

There were no reports of drug-related specific adverse reactions, such as injection site reactions or pruritus, and no abnormalities were observed in the liver panel or in creatine kinase levels. None of the patients had unexplained fluctuations in blood concentrations of immunosuppressant drugs, episodes of graft rejection, or infections. Treatment was discontinued in only 1 patient, at the patient's own request (patient 2). Patient 3 experienced 2 acute non-Q-wave myocardial infarctions at 2 and 7 months after starting PCSK9i and an ischemic stroke at 12 months. The same patient had been hospitalized 3 years earlier due to unstable angina, and coronary angiography revealed GVD affecting 1 vessel, which was revascularized. Additionally, from the time the patient started alirocumab $75 \mathrm{mg} / 14 \mathrm{~d}$, he had been taking only ezetimibe $10 \mathrm{mg} / \mathrm{d}$ due to statin intolerance, with LDL-C levels $>100 \mathrm{mg} / \mathrm{dL}$ persisting until the third cardiovascular event. At that time, pitavastatin $1 \mathrm{mg} / \mathrm{d}$ was started; 4 months later, the patient reached the target of LDL-C $<100 \mathrm{mg} / \mathrm{dL}$, experiencing good tolerance and no new adverse events.

In summary, this is the first series in Spain of HT recipients treated with a PCSK9i. To date, only 2 similar series have been published, one with 6 patients and a mean follow-up of 9 months ${ }^{5}$ and another with 10 patients and a mean follow-up of 10 months. ${ }^{6}$ Our series contributes further data with a longer follow-up (nearly 16 months).

These results indicate the potential safety and efficacy of PCSK9i for treating hypercholesterolemia in HT recipients, although larger studies with longer follow-up are needed to confirm this hypothesis and to evaluate the effects in terms of cardiovascular morbidity and mortality.

\section{FUNDING}

Study cofunded by the European Regional Development Fund (ERDF) through the Biomedical Cardiovascular Diseases Network (CIBERCV), Carlos III Health Institute, Madrid, Spain. 
Table 1. Baseline characteristics and trend in LDL-C levels in HT recipients receiving treatment with a PCSK9i agent (alirocumab 75mg/14d)

\begin{tabular}{|c|c|c|c|c|c|c|c|c|}
\hline Patient & Age, y & $\begin{array}{l}\text { Time since HT, } \\
\mathrm{y}\end{array}$ & IS regimen & Initial statin & Final statin & $\begin{array}{l}\text { Duration of treatment with PCSK9i, } \\
\text { mo }\end{array}$ & $\begin{array}{l}\text { Baseline LDL-C, } \\
\mathrm{mg} / \mathrm{dL}\end{array}$ & $\begin{array}{l}\text { Final LDL-C } \\
\mathrm{mg} / \mathrm{dL}\end{array}$ \\
\hline 1 & 68 & 9.1 & TAC+EVL+corticosteroids & Rosuvastatin $40 \mathrm{mg} / \mathrm{d}$ & Rosuvastatin $20 \mathrm{mg} / \mathrm{d}$ & 15 & 175 & 67 \\
\hline 2 & 48 & 9 & CsA+MMF+corticosteroids & Rosuvastatin $40 \mathrm{mg} / \mathrm{d}$ & Rosuvastatin $40 \mathrm{mg} / \mathrm{d}$ & 5.6 & 180 & 98 \\
\hline 3 & 58 & 10.5 & TAC+EVL+corticosteroids & No & Pitavastatin $1 \mathrm{mg} / \mathrm{d}$ & 21.4 & 129 & 69 \\
\hline 4 & 73 & 13.4 & CsA+EVL+corticosteroids & Pitavastatin $4 \mathrm{mg} / \mathrm{d}$ & Pitavastatin $4 \mathrm{mg} / \mathrm{d}$ & 23.6 & 146 & 35 \\
\hline 5 & 59 & 22.9 & TAC+EVL+corticosteroids & Rosuvastatin $40 \mathrm{mg} / \mathrm{d}$ & Rosuvastatin $40 \mathrm{mg} / \mathrm{d}$ & 12.3 & 146 & 38 \\
\hline
\end{tabular}

CsA, cyclosporin A; EVL, everolimus; HT, heart transplantation; IS, immunosuppression; LDL-C, low-density lipoprotein cholesterol; MMF, mycophenolate mofetil; PCSK9i: proprotein convertase subtilisin/kexin 
A

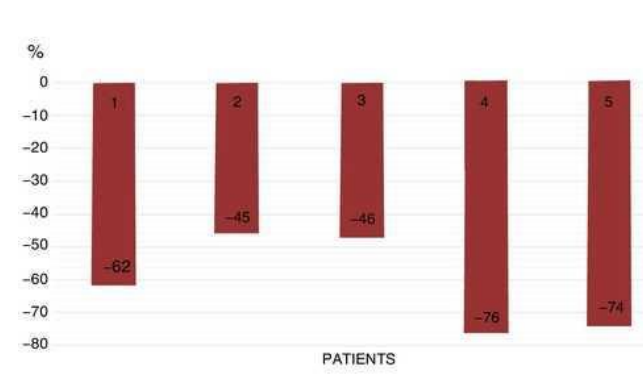

C

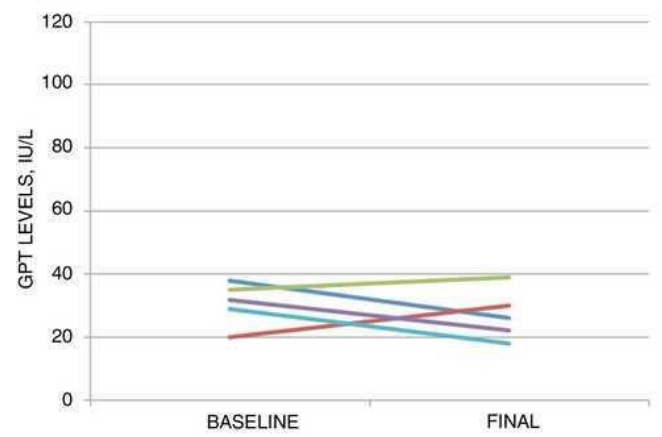

\section{B}

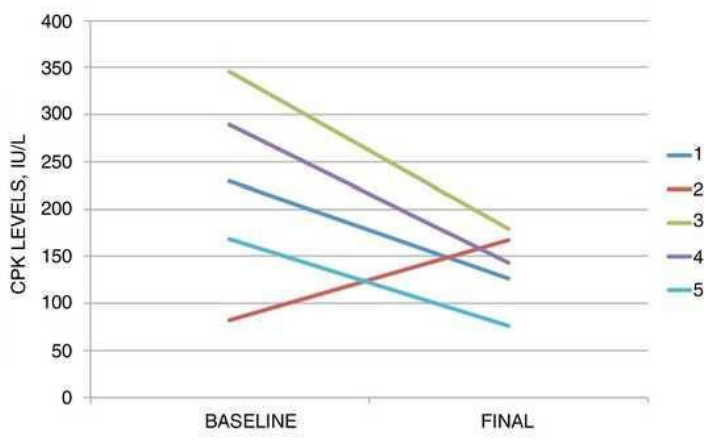

D

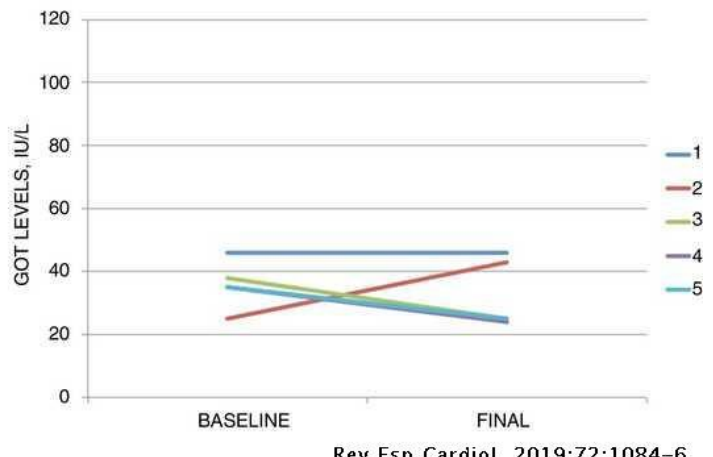

Figure 1. A, percent reduction in low-density lipoprotein cholesterol after the start of treatment with a proprotein convertase subtilisin/kexin type 9 inhibitor (PCSK9i) (alirocumab 75mg/14d). B-D, trend for creatine kinase (CPK), glutamic-pyruvic transaminase (GPT), and glutamic-oxalacetic transaminase (GOT) levels (baseline and end of follow-up) during PCSK9i therapy.

\section{REFERENCES}

1. Nath J, Foster E, Heidenreich PA. Impact of tricuspid regurgitation on long term survival. J Am Coll Cardiol. 2004;43:405-409.

2. Amat-Santos IJ, Castrodeza J, Nombela-Franco L, et al. Tricuspid but not mitral regurgitation determines mortality after TAVI in patients with non severe mitral regurgitation. Rev Esp Cardiol. 2018;71:357-364.

3. Killic A, Saha-Chaudhuri P, Rankin JS, Conte JV. Trends and outcomes of tricuspid valve surgery in North America: an analysis of more than 50,000 patients from the Society of Thoracic Surgeons database. Ann Thorac Surg. 2013;96:1546-1552.

4. Becerra-Muñoz VM, Rodríguez-Capitán J, Sánchez-Espín G, Such-Martínez M, Gómez-Doblas JJ, De TeresaGalván E. Resultados del tratamiento quirúrgico de la insuficiencia tricuspídea grave en una serie contemporánea. Rev Esp Cardiol. 2019;72:178-180.

5. Campelo-Parada F, Lairez O, Carrié D. Percutaneous treatment of the tricuspid valve disease: new hope for the "forgotten" valve. Rev Esp Cardiol. 2017;70:856-866.

6. Toggweiler S, De Boeck B, Brinkert M, et al. First-in-man implantation of the Tricento transcatheter heart valve for the treatment of severe tricuspid regurgitation. Euro-Intervention. 2018;14:758-761. 